REVES - Revista Relações Sociais, Vol. 04 N. 02 (2021)

https://periodicos.ufv.br/ojs/reves

doi: 10.18540/revesvl4iss2pp11446-01-15e

OPEN ACCESS - eISSN: 2595-4490

\title{
Educação infantil e educação em direitos humanos: a construção de uma cultura de paz desde o nascimento
}

Childhood education and human rights education: the building of a peace culture since birth

Joedson Brito dos Santos ${ }^{1}$, Francisca Rodrigues Lopes ${ }^{2}$ e Fernanda de Jesus Santos Brito $^{3}$

1 Universidade Federal do Tocantins, Departamento de Educação, Brasil, E-mail: jbsantus@mail.uft.edu.br, ORCID: https://orcid.org/0000-0003-4394-9294

$2 \quad$ Universidade Federal do Tocantins, Departamento de Educação, Brasil, E-mail: france@uft.edu.br, ORCID: https://orcid.org/0000-0003-4412-3523

3 Universidade Metodista de Piracicaba, PPGE/UNIMEP, Brasil, E-mail: nanda.jbrito@uft.edu.br, ORCID: https://orcid.org/0000-0003-2156-6970

\section{A R T I C LE IN F O}

Article history:

Received 2020-11-22

Accepted 2021-05-04

Available online 2021-05-04
Palavras-chave: Educação infantil. Educação em direitos humanos. Cultura de paz. Dignidade humana.

Keywords: Child education. Human rights education. Culture of peace. Human dignity.

RESUMO. O presente artigo discute Educação Infantil e Educação em Direitos Humanos e tem como objetivo apresentar proposições relativas à defesa de que a educação em direitos humanos deve se configurar desde a educação infantil. Tratase de um estudo bibliográfico que traz uma contextualização sobre direitos humanos, considerando avanços e retrocessos. A investigação estabelece uma relação entre direitos humanos e educação como possibilidade para pensar o direito à educação como caminho para educar para a paz. Além disso, discute a educação em direitos humanos como categoria potente para a construção de uma cultura dos direitos humanos e apresenta algumas considerações sobre isso, a partir da educação infantil. Conclui-se que o contato da criança, desde os primeiros anos de vida, com saberes, experiências, exemplos e atitudes que afirmam a dignidade do outro, os valores da igualdade e da diferença, da fraternidade e da coletividade, da liberdade e da ética, poderá trazer contribuições significativas para a construção de uma nova cultura.

ABSTRACT. This article discusses Early Childhood Education and Human Rights Education and aims to present propositions related to the defense that human rights education should take shape from early childhood education. This is a bibliographic study that brings human rights into context, considering advances and setbacks. The investigation establishes a relationship between human rights and education as a possibility to think about the right to education as a way to educate towards peace. In addition, it discusses human rights education as a powerful category for building a human rights culture and presents some considerations about it, starting with early childhood education. It is concluded that the child's contact, from the first years of life, with knowledge, experiences, examples and attitudes that affirm the dignity of the 
other, the values of equality and difference, fraternity and collectivity, freedom and ethics, may bring significant contributions to the construction of a new culture.

\section{Introdução}

Nos últimos anos, a Educação em Direitos Humanos (EDH) tem ganhado significativo espaço no campo das pesquisas, estudos e políticas sociais, no contexto educacional. Essa constatação pode ser verificada a partir de um conjunto de ações e iniciativas ocorridas, no âmbito internacional, latino-americano e nacional, por exemplo: a Década das Nações Unidas para a Educação em matéria de Direitos Humanos; o Programa Mundial para Educação em Direitos Humanos; a criação de instituições, como o Instituto Interamericano de Direitos Humanos; e a criação de diversas comissões de direitos humanos na América Latina, como a Comissão de Justiça e Paz do Uruguai, dentre outros. No Brasil, podemos destacar a criação do Programa Nacional de Direitos Humanos (PNDH), em 1996, que foi reformulado em 2002; o Plano Nacional de Educação em Direitos Humano (PNEDH), lançando em 2003; e o estabelecimento, em 2012, de Diretrizes Nacionais para a Educação em Direitos Humanos (DNEDH), que tem como fundamento o princípio da dignidade humana, "a igualdade de direitos; o reconhecimento e valorização das diferenças e das diversidades, a laicidade do Estado, a democracia na educação, a transversalidade, a vivência e a globalidade; e a sustentabilidade socioambiental" (BRASIL, 2013, p. 9).

A luta pela afirmação dos Direitos Humanos (DH), pela construção de uma cultura de paz e dos $\mathrm{DH}$, por meio da educação, é muito recente no Brasil, contudo, tem dado saltos significativos. As ações tiveram seus primeiros sinais no contexto da luta pela redemocratização do país, e ganhou corpo no decorrer da década de 1990, no mundo e na América Latina. Vários acontecimentos colocaram em destaque a necessidade dos países em construírem uma cultura que respeitasse os direitos humanos, a partir dos processos educacionais.

Nesse contexto, o Brasil, em articulação com outros países da América Latina, começou a desenvolver várias iniciativas, com o intuito de discutir e pensar a educação em e para os DH no país. Dentre elas, foram realizados seminários, fóruns e comissões. Essas ações se multiplicaram "nas diferentes partes do país, promovidos por universidade, associações, movimentos, ONG e órgãos públicos" (CANDAU; SACAVINO, 2013).

O presente artigo discute Educação Infantil e Educação em Direitos Humanos e tem como objetivo apresentar proposições relativas à defesa de que a educação em direitos humanos deve se configurar desde a educação infantil. Trata-se de um estudo bibliográfico que traz uma contextualização sobre direitos humanos, considerando avanços e retrocessos. A investigação estabelece uma relação entre direitos humanos e educação como possibilidade para pensar o direito à educação como caminho para educar para a paz. Além disso, discute a educação em direitos humanos como categoria potente para a construção de uma cultura dos direitos humanos e apresenta algumas considerações sobre isso, a partir da educação infantil.

\section{A história dos direitos humanos entre avanços-retrocessos-avanços: uma breve contextualização}


A história dos $\mathrm{DH}$ se configura a partir de um movimento entre avançosretrocessos-avanços, tanto no âmbito internacional quanto no nacional, em prol do reconhecimento, valorização, afirmação, bem como da denúncia contra a violação dos direitos fundamentais do ser humano. Tal processo se dá por meio de uma batalha de correlação de forças e da articulação dos anseios e demandas dos diversos sujeitos sociais (CANDAU, 2010). De forma semelhante, e como parte conjunta desse processo, está a reflexão e a proposição sobre a luta pela afirmação de uma cultura de paz e dos DH, constituída a partir da educação. Uma educação em e para os DH.

A expressão ou definição de "direitos humanos" é ampla e diversificada. Existem muitas inferências, reflexões e questionamentos em torno da mesma, sobretudo, no sentido de indagar se existem DH universais, ou se essa tradição de DH não se trata de uma formulação particular do ocidente. No entanto, apesar das diversas elucidações, é inegável a necessidade e a atualidade de se discutir e de ratificar a promoção e a propagação de uma cultura dos $\mathrm{DH}$.

De acordo do com Dallari (1998), a expressão "direitos humanos" é uma abreviatura da formulação "direitos fundamentais da pessoa humana". A partir dessa ideia, configura-se um conjunto em necessidades essenciais do ser humano. Sem eles a pessoa humana não consegue existir, desenvolver-se, organiza-se e realiza-se plenamente em sociedade, como também não consegue desfrutar dos benefícios que a vida em sociedade pode lhes proporcionar.

Há dificuldades em datar com exatidão um início para a história dos $\mathrm{DH}$, haja vista que há divergências de posição entre diversos autores. Por isso, é mais aceitável falarmos em evolução da história dos $\mathrm{DH}$, posto que, desde a antiguidade, encontramos sinais e presença da busca pela proteção dos direitos das pessoas, ainda que condicionadas a aspectos da convivência e da organização entre classes sociais, e não, necessariamente, tendo como fonte a própria pessoa humana.

$\mathrm{Na}$ Antiguidade, por exemplo, nos deparamos com tais sinais, como: no código de Hamurabi, Babilônia, século XVIII a.C.; no pensamento de Amenófis IV, Egito, século XIV a.C.; na Filosofia de Mêncio, China, século IV a.C.; na República de Platão, Grécia, século IV a.C.; na Lei das Doze Tábuas (ou Lei das XII) ${ }^{1}$, aproximadamente 450 a.C; no Direito Romano em geral; como também na tradição judaico-cristã. Por meio dessas evidências, constatamos a presença ou sinais de uma preocupação inicial pela normatização das relações entre as pessoas no sentido de protegê-las.

$\mathrm{Na}$ Idade Média, o surgimento da Carta Magna, na Inglaterra, em 1215, por João Sem Terra, traz alguns avanços no desenvolvimento da proteção dos $\mathrm{DH}$, entre eles, a obrigação de que o rei também deveria se submeter às leis, o Ato de Habeas corpus, o direito de propriedade privada. A partir de então, outros dispositivos foram surgindo no sentido de limitar o poder do rei e de garantir os direitos individuais.

Já na idade moderna, a criação de alguns instrumentos tem grande importância no desenvolvimento de mecanismos de proteção de direito, como o tratado de Vertfália, na Alemanha, em 1648, no qual, pela primeira vez, aparece a concepção de "estado moderno" e o conceito de "soberania". A Carta de Direito, no ano de 1689, na Inglaterra, acrescentou na História o princípio da divisão dos poderes e o fim da hierarquia do parlamento. Além disso, a Declaração de Direitos da Virgínia, em 1776, afirmou todo ser humano como titular de direitos fundamentais.

Nesse contexto, alguns acontecimentos também influenciaram a luta por afirmação de direitos, como a Revolução Americana, em 1776, com a declaração de Independência dos Estados Unidos, e, principalmente, a Declaração dos Direitos do

\footnotetext{
${ }^{1}$ O Código de Hamurabi e a Lei das XII Tábuas podem ser consideradas como as primeiras normatizações criadas para regular a conduta, a convivência e a organização da vida em sociedade.
} 
Homem e do Cidadão, em 1789, na Revolução Francesa. Nesse cenário, os DH estavam/estão ligados aos princípios de igualdade, liberdade e fraternidade.

Cabe ressaltar que, tradicionalmente, muitos inserem o início da história dos $\mathrm{DH}$ no contexto da modernidade, mais precisamente no contexto das revoluções liberais, na França, Inglaterra e Alemanha, na segunda metade do século XVIII, bem como em outras experiências como as "treze colônias inglesas da América do Norte, processo formativo dos Estados Unidos da América; e espraiando-se por alguns outros países europeus (Bélgica, Grécia, Alemanha, Itália, entre outros) " (SILVEIRA, 2007, p. 247).

No entanto, é importante destacar que os $\mathrm{DH}$ também são pensados como expressão e fruto das iniciativas e lutas políticas dos movimentos sociais em prol da conquista de direitos fundamentais. Ainda nos séculos XVII e XVIII, é possível constatar a luta das burguesias revolucionárias contra o poder despótico dos Estados absolutistas, nas defesas em favor de que o Estado garantisse segurança, proteção e instrução mínima para as massas. Pensadores como Adam Smith, Rousseau, Condocet, Daton, dentre outros, reivindicavam uma educação como necessidade primária para o povo, principalmente por compreender os malefícios produzidos pela Revolução Industrial e seus desdobramentos, nos séculos XVIII e XIX, que alterou o modo de produção e a vida da sociedade em geral, gerando desemprego, pobreza, opressão e constantes sinais de violação dos $\mathrm{DH}$. Nesse mesmo contexto, foram despontadas diversas manifestações e lutas lideradas por movimentos da sociedade organizada e em favor de melhores condições de trabalho, de justiça e de direitos sociais, a exemplo dos direitos trabalhistas.

É importante destacar que, ao passo que os $\mathrm{DH}$ foram se constituindo como bandeira de luta, a educação também foi se estabelecendo como uma responsabilidade dos estados. É possível observar, por exemplo, que, na Declaração dos Direitos do Homem e do Cidadão, em 1789, já aparece a afirmação da educação como um direito. De acordo com o artigo XXII, $A$ instrução é a necessidade de todos. A sociedade deve favorecer com todo seu poder o progresso da inteligência pública $e$ colocar a instrução ao alcance de todos os cidadãos.

Contudo, vale destacar que a compreensão de direito legada da modernidade clássica aponta limitações que precisam ser superadas. De acordo com Silveira (2007), na modernidade, ainda não dava para falarmos em DH como compreendemos hoje, ainda que estes sejam humanos, pois o que foi proclamado na Bill of Rights e na Declaração dos Direitos do Homem e do Cidadão foram os direitos civis e políticos. Em verdade, aconteceu uma codificação e uma garantia jurídica dos direitos para cada cidadão, membro de seus respectivos estados (SILVEIRA, 2007). Entretanto, não havia uma preocupação com totalidade da humanidade.

Por outro lado, as formulações dos $\mathrm{DH}$, emergidas a partir do século $\mathrm{XX}$, se diferenciam das elaborações anteriores, sobretudo por apresentarem e sistematizarem uma proposta mais abrangente dos direitos, haja vista que corporifica princípios de "universalidade, integralidade, interdependências, indivisibilidade e inviolabilidade" (SILVEIRA, 2007, p. 250).

Tal universalidade se pretende e se propõe resguardar toda espécie humana em sua dignidade e expressar uma cultura que transversaliza as particularidades de todas as culturas, tendo como marco a Declaração Universal dos Direitos Humanos, de 1948. A violação dos $\mathrm{DH}$, em suas diversas formas e modalidades, objetivas e subjetivas, reais e simbólicas, fez com que, em diversas partes do mundo e tempos da história, a humanidade se posicionasse, de alguma forma, contra a violação da dignidade humana. 
Foram diversas experiências desde a modernidade: os horrores da Primeira e Segunda Guerra Mundial, os totalitarismos do nazismo e do fascismo, o genocídio dos judeus, as bombas de Hiroshima e Nakasáki, a Guerra Fria, as experiências de etnocentrismo, imperialismo e de ditaduras que marcaram os diversos continentes. Esses, dentre outros acontecimentos, fizeram emergir no mundo a necessidade da construção de uma cultura de não violação dos $\mathrm{DH}$ e, consequentemente, a urgência de uma educação para e em $\mathrm{DH}$. Desse modo, a luta pela afirmação dos direitos fundamentais da pessoa humana se tornou uma bandeira internacional.

Dentro da compreensão de que a afirmação dos $\mathrm{DH}$ é algo fundamental no respeito à dignidade de todos, foi constituída, em 1948, a Declaração Universal dos Direitos Humanos. Também foi nessa perspectiva e contexto que surgiu a Declaração Americana dos Direitos e Deveres do Homem, ainda em 1948; a Convenção Americana sobre DH, em 1969, na Costa Rica; e a Convenção Europeia dos Direitos do Homem e das Liberdades Fundamentais, no ano de 1989. Nesse mesmo contexto, foi engendrada a necessidade da construção de uma educação para os $\mathrm{DH}$.

\section{Direitos humanos e a educação: o direito à educação como possibilidade de educar para a paz}

A partir da Declaração Universal dos Direitos Humanos, é possível verificar, de forma mais clara, que a educação precisa ser compreendida não apenas como um direito, mas como um instrumento fundamental para a construção de uma cultura dos $\mathrm{DH}$ e de paz. No Artigo XXVI, inciso segundo, ela dispõe:

a instrução será orientada, no sentido do pleno desenvolvimento da personalidade humana e do fortalecimento do respeito pelos direitos humanos e pelas liberdades fundamentais. A instrução promoverá a compreensão, a tolerância e a amizade entre todas as nações e grupos raciais ou religiosos, e coadjuvará as atividades das Nações Unidas em prol da manutenção da paz. (Assembleia Geral da ONU, 1948).

A educação, tanto nos pressupostos da Declaração, quanto das experiências advinda dos movimentos sociais, apontaram uma educação como possibilidade de fortalecimento do respeito à dignidade dos demais seres humanos. Ensinar DH se constituía uma possibilidade de os sujeitos se (re)significarem politicamente e humanamente, e passarem de um sujeito de mera reprodução para um sujeito de ruptura e transformação da realidade. No entanto, muitos foram os desafios e as dificuldades que representaram limites e barreiras à Declaração Universal dos Direitos Humanos e, consequentemente, impuseram entraves para a construção de uma cultura dos $\mathrm{DH}$, como a própria Guerra Fria.

Ocorreram, a partir da década de 1960, inúmeros acontecimentos que influenciaram e contribuíram para a luta pela afirmação dos $\mathrm{DH}$, como as intensas lutas a favor da descolonização na e da Ásia e África, contra o Apartheid na África do Sul, o Movimento Negro nos Estados Unidos e os movimentos feminista e estudantil em várias partes do mundo (SILVEIRA, 2007). No Brasil, o período de Regime Militar representou um período intenso de violação dos $\mathrm{DH}$, bem como de luta intensa contra tal violação.

No âmbito legal, e internacional, destacam-se também as Conversões de Genebra I, II, III, IV; a Declaração sobre os Direitos dos Povos à Paz, em 1984; a Carta Africana dos Direitos dos Povos, em 1981; a Declaração dos Direitos da Criança, em 
1959; a conversão sobre os Direitos da Criança, em 1989; a Convenção relativa à luta contra a discriminação na esfera do Ensino, de 1960; e os Pactos dos Diretos Civis e Políticos e Pactos dos Direitos Econômicos, Sociais e Culturais, ambos de 1966. Nesse último, há um destaque da educação como um direito intrínseco e um meio indispensável para a realização dos demais direitos. O Pacto dos Direitos Econômicos, Sociais e Culturais dispõe que a educação pode desempenhar um importante papel no desenvolvimento da dignidade da pessoa humana, na promoção dos $\mathrm{DH}$, na democracia e na proteção do meio ambiente.

Uma crescente focalização na EDH ocorreu a partir de 1978, com o Congresso de Ensino de Direitos humanos em Viena, que reafirmou a asseveração dos direitos e da dignidade humana a partir do ensino. Além desse, aconteceram o Congresso Internacional de Direitos Humanos da informação, Ensino e Documentação, em Malta, 1987; o Congresso Internacional sobre Educação para os Direitos Humanos e Democracia, Túnis; e o Congresso Internacional sobre EDH e Democracia, em Montreal, 1993.

Todavia, foi a II Conferência de Viena, realizada em 1993, organizada pelas Nações Unidas, que deu o passo decisivo para a configuração da educação em e para os DH. Nessa conferência, foi instaurado um Plano Mundial de Ação para a EDH, que dispõe sobre o compromisso dos Estados com a inserção dos DH no currículo, no nível formal e informal de ensino (art.79) e explicita os temas a serem trabalhados na $\mathrm{EDH}$, entre outros aspectos. Além disso, foi promulgada a Década Internacional da Educação em Direitos humanos, como estratégia para desenvolver uma cultura universal dos $\mathrm{DH}$, período que foi de $1^{\circ}$ de janeiro de 1995 a 31 de dezembro de 2004, e que reafirmou a educação em $\mathrm{DH}$ como parte do direito à educação em que governos se comprometeriam com a construção de uma cultura de paz, a partir da educação e formação de um novo cidadão.

A discussão sobre $\mathrm{DH}$ aconteceu de forma tardia no Brasil. Embora algumas lutas anticoloniais e antiescravistas, nos séculos XVII e XIX, já defendessem princípios como o de liberdade, que é fundamental dentro do debate sobre $\mathrm{DH}$, as mesmas não ocorreram em função dessa bandeira. De forma semelhante, por mais que o Brasil também tivesse assinado a Declaração Universal dos Direitos Humanos de 1948, nas décadas seguintes, o país protagonizou um período de constante violação dos $\mathrm{DH}$, com os horrores da ditadura. Por outro lado, foi também nesse contexto que o país começou a despertar sua luta pelos direitos da pessoa humana e, consequentemente, pela construção de uma educação para os $\mathrm{DH}$.

A discussão sobre EDH começou a "ganhar campo, de maneira informal, como os movimentos sociais organizados na luta contra a ditadura militar, durante as décadas de 1960 e 1970" (SILVA, 2010), e, sobretudo, a partir da década de 1980, no contexto da redemocratização do país. Isto é, organizou-se do desejo de construir no Brasil uma sociedade mais democrática, cidadã, justa e fraterna ${ }^{2}$, sem violação da dignidade e do direito de liberdade. A ideia surge também das constantes ações e acordos internacionais no intuito de construir um educar para a paz.

O Brasil criou, em 1995, a Rede Brasileira de Educação em Direitos Humanos e elaborou seu Programa Nacional de Direitos Humanos com sua primeira versão em 1996, a segunda em 2002, a terceira em 2009 e com uma atualização em 2009. O país criou também o Comitê Nacional de Educação em Direitos Humanos, em 2003, que teve como primeira meta criar a elaboração do Plano Nacional de Educação em

${ }^{2}$ Refere-se à Constituição Federal, de 1988, que define o Brasil como um Estado Democrático de Direito. 
Direitos Humanos, que, após muito debate em vários encontros estaduais, foi apresentado ao Estado brasileiro no final do ano de 2006. Além dessas, outras iniciativas têm sido desenvolvidas no sentido de tornar a educação em DH uma realidade no Brasil, como: a criação de especializações, lato e stricto sensu, grupos de estudos e pesquisas, e mais recentemente, em 2012, a promulgação das diretrizes nacionais para a educação em $\mathrm{DH}$.

Hoje, de fato, disseminada no país, a EDH se constitui num "conjunto de atividades de educação, de capacitação e de difusão de informação, orientadas para criar uma cultura universal de direitos humanos". Além da promoção de conhecimentos relativos aos $\mathrm{DH}$ e de seus instrumentos e mecanismos de proteção, configura-se numa proposta educativa que visa mediar a construção e ou o aperfeiçoamento de competências "necessárias para promover, defender e aplicar" e respeitar os direitos fundamentais do ser humano no dia a dia da vida em sociedade. Além disso, é necessário que as atividades sejam de natureza prática, articulando a relação entre os $\mathrm{DH}$ e o contexto cultural das vivências dos educandos (UNESCO, 2006, p. 01).

\section{Educação em e para os direitos humanos e a construção de uma cultura dos direitos humanos}

A educação constitui o alicerce e os fundamentos essenciais que dão condições à evolução dos próprios processos educativos, que possibilitam evolução dos sujeitos. Ela possibilita aos indivíduos apreender os conhecimentos necessários para sua inserção e vivência na sociedade, bem como para seu desenvolvimento (SILVA, 2010). Nessa perspectiva, a escola tem como objetivo transmitir conhecimentos sistematizados e capazes de possibilitar o desenvolvimento dos sujeitos para a boa convivência social, de desenvolver uma cultura de respeito às pessoas, independente de condições sociais, econômicas, culturais, religiosas. Por essa razão, a educação se constitui como um direito imprescindível para a garantir outros direitos, um direito que pode assegurar a compreensão, o exercício, a luta e a afirmação de outros $\mathrm{DH}$.

A EDH pode ser definida como um conjunto de atividades voltado e orientado para a construção de uma cultura universal de $\mathrm{DH}$. Trata-se de uma educação que proporciona, além dos conhecimentos teóricos, a mediação de informações e aptidões necessárias para promover, proteger e favorecer os direitos da pessoa, além de despertar, nos sujeitos, a mudança de comportamento e atitudes. Ademais, nesse conceito, visa-se uma educação que seja capaz de possibilitar a superação de uma cultura de desvalorização, desrespeito e exploração das massas populares, desde o período da colonização portuguesa sobre o Brasil ${ }^{3}$ (SILVA e TAVARES, 2010).

De acordo com o Programa Mundial, o PNEDH, ela é:

um processo sistemático e multidimensional que orienta a formação dos sujeitos de direitos, articulando as seguintes dimensões: a) apreensão de conhecimentos historicamente construídos sobre direitos humanos e a sua relação com os contextos internacional, nacional e local; b) afirmação de valores, atitudes e práticas sociais que expressem a cultura dos

\footnotetext{
${ }^{3} \mathrm{O}$ que requer que (re)pensemos a cultural brasileira, marcada por sinais de violação de direitos fundamentais da pessoa humana, com baixa ou pouca incidência de luta pelos direitos do povo brasileiro, e que pensemos a construção de uma nova cultura. Uma cultura de valorização, fortalecimento e respeito à dignidade humana, em todas suas dimensões, por meio da afirmação dos direitos humanos.
} 
direitos humanos em todos os espaços da sociedade; c) formação de uma consciência cidadã capaz de se fazer presente nos níveis cognitivo, social, ético e político; d) desenvolvimento de processos metodológicos participativos e de construção coletiva, utilizando linguagens e materiais didáticos contextualizados; e) fortalecimento de práticas individuais e sociais que gerem ações e instrumentos em favor da promoção, da proteção e da defesa dos direitos humanos, bem como da reparação das violações (BRASIL, 2006, p.17).

A EDH vai para além da contextualização, caracterização e relação dos $\mathrm{DH}$ com as demais dimensões da vida humana em sociedade, bem como do conjunto de conteúdos que tratam dos processos históricos de violação dos $\mathrm{DH}$, das legislações, pactos e ações e estratégias para garantir e afirmar os direitos da pessoa humana. Trata-se de uma proposição que convida o sujeito ao desenvolvimento e ao amadurecimento de valores, comportamento ético e atitudes em prol de uma cultura dos direitos (VIOLA, 2010).

Tem como finalidade:

a) Fortalecer o respeito aos direitos humanos e às liberdades fundamentais;

b) Desenvolver plenamente a personalidade humana e o sentido da dignidade do ser humano;

c) Promover a compreensão, a tolerância, a igualdade entre os sexos e a amizade entre todas as nações, os povos indígenas e os grupos raciais, nacionais, étnicos, religiosos e lingüísticos;

d) Facilitar a participação efetiva de todas as pessoas numa sociedade livre e democrática na qual impere o Estado de direito;

e) Fomentar e manter a paz;

f) Promover um desenvolvimento sustentável centrado nas pessoas e na justiça social (UNESCO, 2006, p. 10).

O enfoque tem como base os direitos sociais, uma vez que a EDH faz parte do direito da criança e tem como perspectiva assegurar processos educativos que vão além dos conhecimentos de leitura, escrita, aritmética, dentre os demais conteúdos comumente focalizados da educação formal regular.

Para fomentar, disseminar e implementar a EDH, a comunidade internacional firmou acordos e estratégias de ações, como a criação de um Programa Mundial, a partir de 2005, com várias etapas e que teve como primeira, a criação de um Plano de Ação ${ }^{4}$, para 2005-2007, para a integração da educação em DH nos sistemas de ensino primário e secundário.

Contudo, o processo de construção, elaboração e implementação de uma educação para uma cultura do respeito à dignidade dos seres humanos não é fácil, ou simplista. Há limites a serem superados para a produção de uma cultura dos direitos da pessoa humana, como: no próprio discurso dos $\mathrm{DH}$ e no modelo da educação instituído no Brasil; no fato de que a construção de cultura e valores culturais não acontece de forma imediata, basta pensar a própria constituição dos $\mathrm{DH}$; e na

\footnotetext{
${ }^{4}$ O plano tem base nos princípios e marcos estabelecidos na Declaração Universal de Direitos Humanos, na Convenção sobre os Direitos da Criança, na Declaração e o Programa de Ação de Viena, na Declaração e Plano de Ação Integrado sobre a Educação para a Paz e nas declarações postas nos programas internacionais em matéria de educação (UNESC, 2006, p. 12).
} 
configuração do modelo de educação vivenciado no Brasil, que não foram pensados de uma hora para outra.

Cabe ressaltar que existem, no discurso sobre o direito, algumas limitações que precisam ser superadas. Para Candau (2008), o discurso dos DH está marcado por forte polissemia, e, consequentemente, as maneiras de se compreender a educação em DH também. Para essa autora, é possível distinguir pelo menos duas abordagens.

A primeira está marcada pela ideologia neoliberal e tende a olhar os "direitos humanos como uma estratégia de melhorar a sociedade dentro do modelo vigente, sem questioná-lo. Enfatizando diretrizes individuais e as questões éticas dos direitos cíveis e políticos". Assim, são abordados temas, como a discriminação racial e de gêneros, preconceitos, violência, segurança, drogas, sexualidade, tolerância e meio ambiente (CANDAU, 2010, p.89).

A segunda "parte de uma visão dialética e contra hegemônica, em que os direitos humanos, são vistos como mediações para construção de um projeto alternativo, sustentável e plural”. Dessa forma, defende uma concepção de cidadania coletiva, favorece a organização da sociedade civil e prioriza atos de sociais comprometidos com a transformação social (CANDAU, 2010, p. 89).

Candau (2008) reconhece que esses enfoques, em muitos aspectos e casos, se combinam e caminham juntos, "praticamente, não existindo em Estado puro" ( $p$. 90). No entanto, o mais importante é ter consciência e percepção de que a matriz predomina nos discursos sobre os $\mathrm{DH}$ e, principalmente, na opção e na escolha da direção em que se pretende caminhar, porque, por trás de um discurso de $\mathrm{DH}$, também é possível legitimarmos as desigualdades e injustiças.

Esse alerta, quanto ao discurso dos $\mathrm{DH}$, já havia sido feito antes por Santos (2006), ao considerar que seja necessária uma ressignificação dos DH. Para este autor, a questão dos $\mathrm{DH}$, no contexto da globalização contemporânea, caracteriza-se por dois movimentos: um hegemônico, que parte de cima para baixo; e outro contrahegemônico, que emerge de baixo para cima.

No primeiro, é possível verificar dois outros movimentos: o localismo globalizado e o globalismo localizado (SILVEIRA, 2007). O localismo globalizado é o processo pelo qual uma determinada realidade é globalizada com sucesso. O globalismo localizado é, na verdade, o reflexo ou impacto nas condições locais das práticas da globalização transnacionais. No segundo, destaca-se o cosmopolitismo insurgente e subalterno, no qual se destaca a "resistência organizada transnacionalmente contra os localismos globalizados e os globalismo localizados, e o patrimônio comum da humanidade", fruto e manifestação das lutas transnacionais, demandas e valores globais, comuns a todos, como o próprio planeta (CANDAU, 2010, p. 208).

No contexto desse raciocínio, é necessário pensar e propor uma globalização contra-hegemônica, por meio da elaboração ou construção de uma nova cultura e mentalidade, que tenha no respeito aos DH seu horizonte. Todavia, é necessário que tenha como prioridade uma dimensão intercultura (SANTOS, 2006), além de valorização entre as diversas culturas, de forma que permita a superação da dicotomia entre identidade e diferença, com uma articulação e proposição da identidade na diferença e vice-versa. A consideração aos direitos e a dignidade do ser humano perpassa necessariamente pela compreensão e afirmação das diferenças, mediante ao reconhecimento e à valorização das identidades.

No caso do Brasil, é fundamental considerar que a sociedade brasileira é marcada, historicamente e culturalmente, pela colonização, exploração, exclusão e desigualdade social, racial e cultural. Além disso, o país apresenta uma cultura "desprovida" de experiências significativas de democracia, de cidadania, de liberdade, 
de justiça e de direito, elitista e segregada. Foi marcada, recentemente, pelos horrores da ditadura, por um crescente desejo de democracia e por um modelo de Estado fundamentalmente neoliberal, que, portanto, prioriza, em suas políticas públicas, os direitos civis e políticos, em detrimento dos sociais, econômicos e coletivos.

Silva e Tavares (2010), ao discutirem essa temática, destacam que:

a história da formação da sociedade brasileira esteve marcada por uma cultura de exploração, violência e extermínio da população negra e indígena, submetidas ao processo de escravidão que durou quase quatrocentos anos. O que evidência que o tratamento a essa população não foi condizente com o respeito ao ser humano. (SILVA E TAVARES, 2010, p. 15).

Também, no período republicano, o país conviveu com outros tantos períodos de autoritarismo ditatorial. Mesmo no contexto mais recente de Estado democrático, nos deparamos com graves e inúmeras situações de injustiça social, concentração de renda e extrema desigualdade. São mais de 7,5 milhões de pessoas que vivem no Brasil apenas com um dólar por dia; $10 \%$ da população ainda concentram $75,4 \%$ de todas as riquezas do país; e, no campo da educação, em 2007, 10\% da população na faixa etária de 15 ou mais anos de idade não estão alfabetizados (SILVA E TAVARES, 2010).

Essa realidade vinha sendo enfrentada com mais atenção desde o início dos anos 2000. Todavia, quando observamos a realidade da desigualdade no país, a partir do critério-base do Banco Mundial, que é de US\$1,90 por pessoa/dia, constatamos que havia em 2016, no Brasil, cerca de 13,3 milhões de pessoas em situação de pobreza, cerca de $6,5 \%$ da população. No ano de 2017, esse dado saltou para 15 milhões, o que representou $7,2 \%$ da população. Foi o terceiro ano consecutivo de crescimento, o que caracteriza uma tendência. O país voltou a registrar alta taxa de mortalidade infantil, que passou 13,3 mortes, em 2015, para 14 mil, em 2016. Algo que não acontecia desde o início de anos de 1990.

Para Silva e Tavares (2010), é preciso repensar o modelo ou a noção de cidadania que predomina no Brasil. Há que ultrapassar uma cidadania formal, centrada nos elementos legais e formalista. É preciso uma cidadania ativa, que represente, substancialmente, a participação da sociedade civil nos destinos da sociedade brasileira. Essa temática é bastante trabalhada por Benevides (1991), que defende a participação e a pressão popular como condição fundamental para transformação social, como possibilidade de intervenção e ação frente ao poder público instituído.

Para Benevides (1991), a cidadania passiva reside no fato de todos estarmos sujeitos e/ou submissos às leis jurídicas, que garantem direitos e deveres, uma cidadania distante dos contextos sociopolíticos, ético e cultural dos sujeitos. A cidadania ativa é a participação dos sujeitos na luta e no exercício de seus direitos e deveres, na responsabilidade e atuação de cada um para com o exercício do poder. É fundamental o desenvolvimento da autonomia do grupo ou indivíduo, bem como a participação nas tomadas de decisões relativas aos interesses da população.

Nessa perspectiva, é fundamental pensar e repensar o conceito de democracia vivenciado no Brasil, visto que ela se manifesta de forma limitada e se apresenta muito mais como um elemento formal que um efetivo exercício da liberdade e da igualdade. Nos termos defendidos por Bobbio (1992), a democracia é condição fundamental para o exercício da cidadania ativa, uma vez que, sem ela, não é possível o princípio da 
liberdade e da igualdade. Para Bobbio (1992), a democracia se funda na definição de um conjunto de regras pensada pela própria coletividade e tem em vista garantir o maior exercício e participação dos sujeitos nas decisões coletivas.

Diante dessas proposições quanto à EDH, como também seus limites, observamos que não é somente de produzir essa nova perspectiva e apenas apresentar novos conceitos, metodologias e novos recursos. Trata-se de apresentar um novo comportamento, atitude e posicionamento. De criar outra mentalidade, de pensar outro sujeito. Em outras palavras, é necessário construir uma nova cultura. Logo, o processo é denso e não se pode pretender atingir seus objetivos aligeradamente. É necessário repensar conceitos, reviver memórias e ressignificar a história.

Sendo assim, quando falamos em EDH também nos referimos a uma realidade complexa, inserida nos termos e no contexto da construção de uma nova cultura, uma cultura de Paz e de valorização da dignidade humana. Sendo assim, trata-se de transformar, dimensionar ou direcionar o fazer educativo para elaboração de uma nova cultura ou uma contracultura, para a formação de uma contra-hegemonia, haja vista que existe uma cultura que faz hegemônica a violação e a negação dos valores humanos, em função do consumo extremo, por parte da massa, e do lucro cada vez maior, por parte do grande empresariado e das grandes corporações.

A abordagem presente neste texto precisa ser problematizada ${ }^{5}$, sobretudo no que tange à noção de $\mathrm{DH}$, em virtude do viés ideológico, eurocêntrico e liberal que a sustenta. Tal concepção confunde a noção de direito como uma concepção de serviço assistencialista e se apresenta como uma estratégia de controle e alienação para as classes menos favorecidas e os países em desenvolvimento.

\section{Educação para os direitos humanos desde a educação infantil: algumas considerações}

Neste texto, defendemos e propomos que a construção de uma cultura dos DH pode ter como prioridade e ponto de partida a educação da criança pequena. A construção de uma cultura de paz deve começar e perpassar, necessariamente, pela garantia do direito à educação desde o nascimento, como também deve atravessar a ideia de que essa educação, na infância, deve ter, entre seus eixos centrais, a educação em e para os DH. Assim, o contato da criança, desde os primeiros anos de vida, com saberes, experiências, exemplos e atitudes que afirmam a dignidade do outro, regido pelos valores da igualdade e da diferença, da fraternidade e da coletividade, da liberdade e da ética, poderá trazer contribuições significativas para a construção de uma nova cultura.

Há algumas razões que nos fazem levantar essa bandeira. Primeiro, compreendemos que o ser humano é um ser social e o seu desenvolvimento e formação "são resultados do desenvolvimento metódico de toda humanidade". As funções psicológicas, características especificamente humanas, surgem inicialmente no coletivo e, somente depois, elas se tornam funções internas (VIGOTSKI, 2018). Nesse sentido, é por meio da vida em sociedade e das constantes práticas e interações sociais que o ser humano internaliza os elementos sociais, se apropria da cultura e se torna homem. Sobre esse aspecto, Prestes (2010) destaca que, para Vigotski,

\footnotetext{
${ }^{5} \mathrm{O}$ presente texto reconhece a necessidade de problematizar o tema, mas não teve a intenção de fazê-la suficientemente.
} 
A psiquê humana é a forma própria de refletir o mundo, entrelaçada com o mundo das relações da pessoa com o meio. Por isso, as peculiaridades do que é refletido pela psiquê podem ser explicadas pelas condições e visões de mundo do ser humano (PRESTES, 2010, p. 36).

Ou seja, para Vigotski, o desenvolvimento mental tem uma dimensão histórica e seus aportes estão no social e no cultural. Trata-se de um processo contínuo de evolução que acontece ao longo de todo o ciclo vital. Dessa forma, as pessoas não nascem preconceituosas, violentas, autoritárias ou racistas, por exemplo, elas aprendem nas relações e se desenvolvem a partir das relações sociais. Assim, também podem aprender, desenvolver e se desenvolver a partir de relações positivas, de uma educação intencionalizada, sensível e estética, estimuladora de boas práticas, de respeito e valorização do outro e das diferenças.

Em segundo aspecto, compreendemos que o trabalho educativo não se restringe ao ensino, mas se configura como um ato que produz, "direta ou indiretamente, em cada indivíduo singular, a humanidade que é produzida historicamente e coletivamente pelo conjunto dos homens" (SAVIANI, 2013, p. 11). Nesse sentido, a educação tem como principal função disponibilizar e garantir, aos seres humanos, a cultura historicamente construída, ou seja, os saberes, os valores, os conhecimentos, as expressões culturais e artísticas, o esporte e o lazer, por exemplo. Por isso, tem por finalidade garantir o direito das crianças, jovens, adultos e velhos em aprender. Ela desponta como possibilidade de o ser humano se constituir como sujeito.

Em terceiro aspecto, ressaltamos as contribuições cognitivas/educacionais, sociais, afetivas e econômicas para os sujeitos que tiveram acesso à educação na primeira infância, ou seja, deve-se reconhecer que essa faixa etária é a mais importante e decisiva para a configuração dos processos de desenvolvimento biopsicossocial de qualquer ser humano.

Trata-se de argumentos advindos de diversas ciências que indicam que os primeiros anos de vida de uma criança são os de maior importância para o indivíduo, sendo potente para estimular todo tipo de aprendizagem e desenvolvimento. No viés economicistas, por exemplo, acredita-se que é necessário desenvolver e estimular as capacidades que preparam o indivíduo para a vida futura, para a vida educacional, para a carreira profissional e, por conseguinte, para a produtividade. Portanto, 0 acesso a El pode gerar ganhos, tanto para o indivíduo quanto para os seus familiares, bem como para uma nação (SANTOS, 2019, p. 17).

Por fim, necessário se faz reconhecer a criança, como um sujeito de direitos, e a educação na primeira infância, como um direito fundamental do ser humano desde o nascimento. Nesse sentido, desde cedo, a criança pode e deve ser atendida e acompanhada em suas especificidades e sobre os princípios do educar e do cuidar. Esses, dentre outros aspectos e compreensões colocam em destaque a El como etapa imprescindível para pensarmos a formação e o desenvolvimento do ser humano, bem como o desenvolvimento de autonomia, da liberdade, de atitudes, de comportamentos e de valores que dignificam o ser humano.

A respeito da relação entre infância, educação, cultura contemporânea e $\mathrm{DH}$, Bazílio e Kramer (2011) destacam que o tema da formação cultural e do direito da criança como cidadão deve ter como ideia central a certeza de que, hoje, é preciso educar contra a barbárie. A barbárie não é coisa do passado, pois constantemente convivemos com fatos e notícias de contínuos atos de transgressão aos direitos da 
pessoa humana. Além disso, é importante reconhecermos que as raízes da violação dos $\mathrm{DH}$, no Brasil, são profundas e deixaram marcas. Por essas razões, a EDH deve começar ainda na infância, desde a El.

Bazílio e Kramer (2011) afirmam que é importante ir além da ideia da tolerância como princípio norteador da construção de uma educação que tem como base "o reconhecimento do outro e de suas diferenças de cultura, etnia, religião, classe social, idade". Que precisamos "combater a desigualdade e educar contra uma cultura da barbárie, o que implica uma ética e uma perspectiva de formação cultural que assegure sua dimensão de experiência crítica" (BAZÍLIO e KRAMER, 2011, p. 105).

Os autores fazem algumas indagações sobre como educar crianças numa cultura orientada pelo modelo do capitalismo. A respeito dos diferentes espaços de produção de cultura, temos à disposição sobre o que mundo tem ensinado para as crianças e sobre a produção de políticas para infância que tenham como responsabilidade a humanização das populações infantis. Nesse contexto, Bazílio e Kramer (2011) destacam que é preciso trabalhar numa perspectiva de humanização do ser humano, fazendo o resgate de experiências que demonstrem violação de direitos e/ou que sinalizam necessidades e possibilidades de evidenciar a afirmação de direitos, com atividades que possibilitem o desenvolvimento da capacidade de ler o mundo e de escrever coletivamente a história e sua própria história, sobretudo com a apropriação das mais diversas formas de produção cultural (BAZíLIO e KRAMER, 2011).

Bazílio e Kramer (2011) apontam que precisamos gerar e trabalhar com experiências de educação e socialização, a partir de práticas solidárias entre crianças, jovens e adultos, com experiências, vivências e ações coletivas capazes de gerar atitudes, sentimentos à aprendizagem de valores, bem como de gerar sentido de pertença. Precisamos de espaços de elos de El, capazes de produzir um consenso diferente do que está posto para as crianças na atualidade, a exemplo dos modelos de criança e de infância que são mostrados, diariamente, na mídia.

Desse modo, a escola, a pré-escola e a creche são espaços de circulação de culturas, no plural, ou seja, de tradições, de costumes, valores, vivências e experiências dos diversos grupos sociais. Nesses espaços, há o desenvolvimento de trajetórias e saberes, conhecimentos e experiências da sociedade, do povo da polis. Vale ressaltar que o que ela propõe não é um ensino da literatura e da cultura, mas a ênfase na possibilidade de se construir aprendizagens e valores, a partir das experiências, das artes e dos livros. Nesse sentido, o trabalho com a produção da cultura tem grandes contribuições para a formação das crianças, jovens e adultos, uma vez que esse processo permite o resgate de vivências de experiências capazes de gerar atitudes, comportamentos e mudanças.

Acreditamos que construir uma cultura dos DH não seja simples. É necessário elaborar e produzir esse novo consenso, uma nova ideologia e uma contra-hegemonia tendo como centralidade o ser humano e a sua dignidade. Acreditamos nesse contexto que, a escola tem o papel importante, pois ela é e deve ser lócus primeiro da disseminação de novos valores e conhecimentos, tanto no sentido teórico quanto no sentido das vivências dos mesmos.

No concreto da ação docente e no chão da escola, por meio das relações, tensões, conflitos negociações e emoções, os processos formativos se constituem e os envolvidos também se constituem com eles. Particularmente, no caso da $\mathrm{El}$, é nas interações que a vida acontece que o aprendizado ocorrer e o desenvolvimento e aprendizagem da criança acontece. Dessa forma, a El, enquanto primeira etapa da educação básica, situa-se como momento favorável para formação de novos sujeitos, novos intelectuais e, por conseguinte, para a consolidação de uma hegemonia. 
Nessa perspectiva, a informação, a instrução e, sobretudo, a educação têm papel imprescindível na construção de consciência, de valores e de cultura. Esse processo perpassa, necessariamente, pelo conhecimento de direitos e da história das lutas e contra a violação dos direitos do ser humano. Assim, atravessa também a formação, a vivência e a experiência de valores e atitudes relativas à valorização da dignidade humana. Assim, a EDH tem um duplo movimento. São eles: de mediação de conhecimentos e saberes e de vivência e fazeres.

Defendemos que essa perspectiva de construção de uma cultura contra a violação da dignidade do ser humano comece e perpasse, necessariamente, pela EDH desde a primeira infância, pois assegurar o direito à educação desde a infância é imprescindível para se começar a pensar um novo projeto de escola, de cultura e, consequentemente, de sociedade.

Acreditamos que as contribuições de Gramsci (1982), no caderno 12, possam nos ajudar a pensar os passos para a construção de uma nova hegemonia, ou de uma "contra - hegemonia" e, por conseguinte, a construção de uma nova cultura, nesse texto, entendido como uma cultura dos direitos humanos. Ao mesmo tempo, também defendemos que a Teoria Histórico-cultural se constitua como um campo epistemológico potente para direcionar a ação pedagógica na EI, tendo em vista um desenho de uma EDH a partir e na El. Entretanto, isso é tema para outra discussão.

\section{REFERÊNCIAS}

BAZÍLIO, Luiz Cavaliere; KRAMER, Sonia. Infância, educação e direitos humanos. São Paulo: Cortez, 2011.

BENEVIDES, Maria Victoria de Mesquita. A Cidadania Ativa. São Paulo: Ática, 1991. BOBBIO, Norberto. A era dos Direitos. 8. ed. Rio de Janeiro: Campus, 1992.

BRASIL. PLANO NACIONAL DE EDUCAÇÃO EM DIREITOS HUMANOS. Secretaria Especial de Direitos Humanos. Brasília, MJ/MEC/UNESCO, 2006.

CANDAU, Vera Maria. Direitos Humanos, Diversidade cultural e educação: a tensão entre igualdade e diferença. In: FERREIRA, Lúcia de Fática Guerra; ZENEIDE, Maria de Nazaré Tavares; ALVES, Adelaide Dias. (Orgs). Direitos Humanos na Educação Superior: subsídio para a educação em direitos humanos na pedagogia. João Pessoa: Editora Universitária da UFPB, 2010.

CANDAU, Vera Maria. Multiculturalismo; diferenças culturais e práticas Pedagogicas. 4.Ed.Petrópolis, RJ: Vozes,2010, p. 408.

CANDAU, Vera, e SACAVINO, Susana. Educação em Direitos Humanos e formação de educadores. Educação (Porto Alegre, impresso), v.36, n.1 p. 59-66, jan./abr.2013. DALLARI, D. Direitos humanos e cidadania. São Paulo: Moderna, 1998. p.7-9

DAVIDSON Alastair; WEEKLEY Kathleen. Gramsci e os Direitos Humanos. In: COUTINHO, Carlos Nelson; TEIXEIRA Andréia de Paula. Ler Gramsci, entender a realidade. Rio de Janeiro: Civilização Brasileira. 2003.

DECLARAÇÃO Universal dos Direitos do Homem e do Cidadão. Biblioteca Virtual de Direitos Humanos - Universidade de São Paulo. 2014.

GRAMSCI, Antonio. Os Intelectuais e a Organização da Cultura. São Paulo: Civilização Brasileira, 1982.

PRESTES, Zoia. Quando não é quase a mesma coisa: análise das traduções de Lev Semionovitch Vigotski no Brasil. Repercussões no campo educacional (Tese de Doutorado). Brasília: UNB, 2010

SANTOS, Boaventura Sousa. A gramática do tempo: para uma nova cultura política. São Paulo: Cortez, 2006. 
SANTOS, J. B.. Pressupostos do paradigma do Capital Humano aplicados à Primeira Infância. Revista Brasileira de Educação do Campo - RBEC, v. v, p. 1-30, 2019.

SAVIANI, D. Pedagogia histórico-crítica: primeiras aproximações. 8ª ed. Campinas, SP: Autores Associados, 2013.

SILVA, Ainda Maria Monteiro; TAVARES, Celma (Org). Política e fundamentos da Educação em Direitos Humanos. São Paulo: Cortez, 2010.

SILVEIRA, Rosa Maria Godoy et alii (org.) Educação em Direitos Humanos: fundamentos teórico-metodológicos. João Pessoa: Editora Universitária/UFPB, 2007. UNESCO, Plano de Ação: Programa Mundial para educação em direitos humanos. Organização das Nações Unidas para a Educação, a Ciência e a Cultura. Nova York e Genebra, 2006

VIGOTSKI, Lev Semenovich. Sete aulas de L.S Vigotski sobre os fundamentos da pedologia. (Org. Trad. Zoia Prestes, Elizabeth Tunes). Rio de Janeiro: Papers, 2018. 